\title{
Adherence to Guidelines for Assessment and Empiric Antibiotics Recommendations for Community- Acquired Pneumonia at Ambo University Referral Hospital: Prospective Observational Study
}

This article was published in the following Dove Press journal:

Patient Preference and Adherence

Endalkachew Mekonnen

Eticha (ID)

Workineh Diriba Gemechu ${ }^{2}$

'Ambo University, College of Medicine and Health Science, School of Pharmacy, Ambo, Ethiopia; ${ }^{2}$ Jigjiga University,

College of Medicine and Health Science,

School of Medicine, Jigjiga, Ethiopia
Correspondence: Endalkachew Mekonnen Eticha

Email obsaamiiraa@gmail.com
Objective: The high incidence and substantial morbidity and mortality associated with community-acquired pneumonia necessitate an accurate assessment and appropriate management of patients. This observational prospective study aimed to evaluate the physicians' adherence to the Ethiopian Standard Treatment Guideline for assessment and an empiric antibiotic selection for Community-acquired pneumonia.

Results: The study indicated that the pneumonia severity assessment tool, CURB-65 score, was never used. Of 141 patients referred to an admitting diagnosis of severe communityacquired pneumonia, only 50 were subsequently found to satisfy the guideline criteria, overdiagnosis of $41.9 \%$. Large proportions of the participants $(130,60 \%)$ were prescribed antibiotics in the last three months. The most commonly prescribed single antibiotic was Ceftriaxone $(47,21.7 \%)$, while ceftriaxone plus azithromycin was the most common combination, $110(50.7 \%)$. In general, the extent of non-adherence to the national guideline for the use of antibiotics was $36.4 \%$. In conclusion, the use of CRB 65 scores was uncommon in the study setting. Poor adherence to Ethiopian Standard Treatment Guideline regarding the decision of hospital admission (41.9\%) and the antimicrobial selection $(36.4 \%)$ was determined.

Keywords: standard treatment, adherence, empiric antibiotics, community-acquired pneumonia

\section{Introduction}

Infectious Disease Society of America (IDSA) defined pneumonia as the presence of "new lung infiltrate plus clinical evidence that the infiltrate is of an infectious origin, which include the new onset of fever, purulent sputum, leukocytosis, and decline in oxygenation". ${ }^{1}$ Hospital-Acquired Pneumonia (HAP) is defined as a pneumonia not incubating at the time of hospital admission and occurring 48 hours or more after admission. ${ }^{1}$ Ventilator-Associated Pneumonia (VAP) is defined as a pneumonia occurring $>48$ hours after endotracheal intubation. ${ }^{1}$ The most frequent causative micro-organisms reported in HAP/VAP were Enterobacteriaceae, S.aureus, p.aeruginosa and A.baumannii, and polymicrobial cases. ${ }^{2}$ Some pathogens, like Stenotrophomonas maltophilia has emerged as an important pathogen associated with significant mortality in pneumonia and bacteremia of severely immunocompromised, hospitalized patients. ${ }^{3}$ 
Community-acquired pneumonia (CAP) is an infection of the lung parenchyma, acquired in the community. ${ }^{4}$ In the western countries, CAP occurs in approximately 5.66.11 per 1000 of the adult population per year. ${ }^{5}$ The most common etiologic agents responsible for CAP include Streptococcus. Pneumonia, Mycoplasma Pneumonia, Chylamidial. Pneumonia, or respiratory viruses. ${ }^{5} \mathrm{CAP}$ is a significant cause of morbidity and mortality ${ }^{4}$ and associated with a considerable economic burden on the health care system. ${ }^{6}$ The combination of high incidence and substantial financial costs necessitates accurate diagnosis and appropriate management of patients diagnosed with CAP. ${ }^{4}$

Accurate diagnosis and appropriate prescribing and use of antibiotics is important for mitigating antibiotics resistance crisis. ${ }^{4}$ When infections can no longer be treated by first-line antibiotics due to microbial resistance, more expensive medicines must be used. A longer duration of illness and treatment, often in hospitals, increases health care costs as well as the economic burden on families and societies. It also puts the achievements of modern medicine at risk. Organ transplantations, chemotherapy and surgeries such as caesarean sections become much more dangerous effective antibiotics for the prevention and treatment of infections. $^{7-10}$

The World Health Organization (WHO) identifies vaccination and case management as the most effective guidelines for the management of patients with CAP. These have been demonstrated to reduce mortality and morbidity ${ }^{11-13}$ and shorten the length of hospital admission. ${ }^{14,15}$ Several studies indicated that implementation of treatment guidelines and maintained adherence, reduce morbidity, mortality and health care costs..$^{14,16,17}$ Guidelines can direct and standardize disease management, but the effects on disease outcomes are less measurable. ${ }^{18,19}$ However, shreds of evidence suggest that national guidelines on the management of patients with CAP are often poorly adhered to in clinical practice. ${ }^{14,16,20,21}$ This article discusses the adherence to the Ethiopian Standard Treatment Guideline (ESTG) ${ }^{22}$ in the Ambo University Referral Hospital (AURH).

\section{Methods}

\section{Study Area and Period}

The study was conducted in AURH which is $126 \mathrm{~km}$ from the capital city Addis Ababa, Ethiopia. The hospital provides services for approximately greater than 20,000 populations annually with a total of 250 beds. The study was conducted from January to April 2019.

\section{Study Design and Study Participants}

An observational prospective study was conducted on consecutive adult patients (aged $\geq 15$ years) diagnosed for CAP in the study settings. The decision for hospitalization is independent of the authors and it was a decision of attending physicians.

Patients with aspiration pneumonia, hospital-acquired pneumonia, exacerbations of chronic pulmonary diseases, patients diagnosed with pulmonary tuberculosis (TB) and immunocompromised were excluded from the study. Patients not prescribed antibiotics on the first day of admission were also excluded. Patients were diagnosed for pneumonia depend on the ESTG for General Hospitals $^{22}$ and physicians clinical judgment.

\section{Data Collection Instruments and Techniques}

The diagnosis of CAP relies on the presence of selected clinical sign and symptoms and investigations. ESTG ${ }^{22}$ suggests the use of CURB-65 (C-confusion; U-uremia or blood urea nitrogen $(\mathrm{BUN}) ; \mathrm{R}$ - respiratory rate; $\mathrm{B}$ Blood pressure and age greater than 65) score to classify the severity and determines hospitalization. However, due to the lack of laboratory result for BUN from patients' medical record, we modified CURB-65 to CRB-65 score instead. Each variable has one point and evaluated out of 4 points. A patient with CRB- 65 score less than or equal to 1 point is treated as outpatients. If the score is greater than 1 point, the patient needs hospitalization. A Patient with high score of a CURB-65 has high risk of mortality. ${ }^{4,22}$

A structured questionnaire was used to record the relevant data for eligible patients. The data collection tool was provided in Supplementary file 1. The first assessment of the patients started on the first day of hospital admission. The 2nd and 3rd assessments were over 48 hours of admission and on the day of discharge, respectively. The socio-demographic data of the enrolled patients were collected at assessment 1 and includes age, sex, marital status, and occupational status. The following parameters were recorded on admission and re-assessment periods: clinical signs (body temperatures, heart rate, respiratory rate and arterial blood pressure) and symptoms, partial oxygen saturation, radiographic (chest X-ray, CXR), and antibiotic 
regimens. Microbiological data were also recorded from the patients' medical records.

Antibiotics were received after diagnosed for CAP. The ESTG $^{22}$ recommends an empiric therapy of macrolides or doxycycline antibiotics for mild CAP (ambulatory patients) with no history of antibiotic use within the last 3 months. If prior antibiotics use within the last 3 months, combinations of macrolides plus amoxicillin or amoxicillin-clavulanate were recommended. For severe CAP, empiric antimicrobial therapy of advanced cephalosporin's (3rd or 4th generations) or benzylpenicillin in combination with macrolides was initiated. All empiric regimens are subject to modification on the arrival of microbiological results and other evidence. De-escalation to narrowspectrum antibiotics and oral regimens are always encouraged in the appropriate circumstances.

The antibiotic prescribed during the first 24 hours of hospitalization was considered to be the initial treatment. Prior antimicrobial regimen received for the current diagnosis in the outpatient setting was also recorded. All initial empirical antimicrobial therapy, whether or not adhering to the guideline, was recorded. Antimicrobial regimen was defined as ESTG adherent when the antibiotics chosen by the physician followed the recommendations included in the $2014 \mathrm{ESTG}^{22}$ regardless of any additional antibiotics received. The physicians were also called adherent to the guideline if they decided patients hospitalization and discharge using CURB-65 criteria.

\section{Data Processing and Analysis}

The collected data were cleaned, edited, categorized, entered and analyzed into software for Statistical Package for Social Science (SPSS) version 20. Proportions' were calculated using descriptive analysis. The results were displayed by using tables for simple interpretation and understandings.

\section{Results}

\section{Socio-Demographic Characteristics}

An observational prospective study of 217 CAP patients consecutively admitted to AURH was conducted from January to April 2019. Of the total patients, $55.3 \%$ were females and $74.7 \%$ were less than 65 years of age. The median duration of hospital stay was 4 days. Of the total study patients, $8.3 \%$ and $43.3 \%$ of them had an altered mental status and $R R \geq 30$ at presentation, respectively, as
Table I Socio-Demographic and Clinical Characteristics of CAP Patients Admitted to AURH from January to April 2019

\begin{tabular}{|c|c|}
\hline Baseline Characteristics & $\mathbf{N}(\%)$ \\
\hline \multicolumn{2}{|l|}{ Age (years) } \\
\hline$<65$ & $162(74.7)$ \\
\hline$\geq 65$ & $55(25.3)$ \\
\hline \multicolumn{2}{|l|}{ Sex } \\
\hline Male & $97(44.7)$ \\
\hline Female & $120(55.3)$ \\
\hline \multicolumn{2}{|l|}{ Occupation } \\
\hline Farmer & $75(34.6)$ \\
\hline Student & $28(24.4)$ \\
\hline Civil Servant & $23(22.1)$ \\
\hline Private employee & $16(18.9)$ \\
\hline \multicolumn{2}{|l|}{ Marital status } \\
\hline Divorced & $13(6)$ \\
\hline Married & I55 (7I.4) \\
\hline Single & $49(22.6)$ \\
\hline \multicolumn{2}{|l|}{ Mental status } \\
\hline Confused & $18(8.3)$ \\
\hline Oriented & $199(91.7)$ \\
\hline \multicolumn{2}{|l|}{ Respiratory rate, breaths/min } \\
\hline$\leq 30$ & $123(56.7)$ \\
\hline$>30$ & $94(43.3)$ \\
\hline \multicolumn{2}{|l|}{ Partial pressure of oxygen $\left(\mathrm{PaO}_{2}\right)$} \\
\hline$<90 \%$ & 59 \\
\hline$\geq 90 \%$ & 82 \\
\hline \multicolumn{2}{|l|}{ Arterial blood pressure $(\mathrm{mm} \mathrm{Hg})$} \\
\hline$<90 / 60$ & $37(17.1)$ \\
\hline$\geq 90 / 60$ & $180(82.9)$ \\
\hline \multicolumn{2}{|l|}{ Department } \\
\hline Outpatient treatment & $74(34.1)$ \\
\hline Inpatient treatment & $143(65.9)$ \\
\hline \multicolumn{2}{|l|}{ Severity assessment } \\
\hline Mild pneumonia & $76(35.0)$ \\
\hline Severe pneumonia & $|4|(65.0)$ \\
\hline \multicolumn{2}{|l|}{ Antibiotics history } \\
\hline Not Taken within three months & $87(40.1)$ \\
\hline Taken within three months & $130(60)$ \\
\hline
\end{tabular}

shown in Table 1. All of the patients had no documented blood urea nitrogen (BUN) result.

Of all, 141 (65\%), 84 (38.7\%) and 15 (6.9\%) patients were tested for baseline $\mathrm{O} 2$ saturation, sputum gram stain and sputum bacterial culture, respectively. Large number of patients $(141,65 \%)$ were diagnosed with severe pneumonia and hospitalized. A total of $130(60 \%)$ patients had 
a previous history of antibiotic use within the last three months. Microbiology and drug susceptibility test data were not available in medical records. This is not unexpected for resource-limited settings in which empiric therapy is the most common practice.

None of the patients were assessed using a CRB-65 score, which is indicated in $\mathrm{ESTG}^{20}$ to determine pneumonia severity and subsequent management. According to the severity score, 167 (77\%) patients had mild CAP and should be treated as an outpatient. In contrast, $141(65 \%)$ patients were hospitalized for severe CAP and 76 (35.0\%) were treated as outpatient management according to the physician's diagnosis. Of 141 patients diagnosed for severe CAP, only 50 were subsequently found to satisfy the criteria of the guideline, an over-diagnosis of $41.9 \%$.

\section{Empiric Antibiotics Prescribed to Patients with Community-Acquired Pneumonia}

Based on our assessment, many of the antimicrobial regimens used in our hospitals are not consistent with ESTG and are excessively broad spectrum. Six different antibiotic regimens were prescribed for CAP patients as indicated in Table 2. Ceftriaxone was the most commonly prescribed single antibiotics, 47 (21.7\%), while ceftriaxone plus azithromycin was the most common combination, $110(50.7 \%)$.

Regarding antibiotic selection, 79 (36.4\%) prescriptions were inappropriate. Of these, 42 (19.4\%) prescription of ceftriaxone alone or in combination with azithromycin unnecessarily over-prescribed. Similarly, 6 of coamoxiclav plus clarithromycin and 2 of amoxicillin plus azithromycin combination were over-prescribed. Under- treatment was associated with poor treatment outcome, but such a trend was not apparent in the current study.

\section{Discussion}

To our knowledge, this is the initial study in Ethiopia that investigates the adherence of physicians to national standard treatment guidelines for diagnosis and treatment of pneumonia. CAP is a common diagnosis and results in significant health care costs, mostly for patients who require hospitalization ${ }^{17,23}$ and it is one of the most common infections antibiotics are prescribed.

The study indicated that adherence to CAP guidelines and the use of severity scores for the decision of hospital admission was poor. Although the ESTG ${ }^{22}$ and other CAP management guidelines, such as the Infectious Disease Society of America $^{4}$ have available to physicians, this study shows no recordings of the CAP severity score using the CRB-65. Studies reveal that the documented use of a pneumonia severity score is extraordinarily low $(5 \%){ }^{24,25}$ Besides, several studies showed a very poor recording of the CAP severity score. ${ }^{18,20,26}$ Assessing the CURB-65 score helps physicians to classify patients and select appropriate antimicrobial therapy concerning the patient site of care. Pneumonia severity scores have been demonstrated to improve care for patients with CAP by providing independent predictors of disease severity. ${ }^{27}$ Implementation strategies ${ }^{28}$ are needed to achieve higher adherence rates for the benefit of patient safety and health economy.

The current study shows, $41.9 \%$ of patients were overdiagnosed and hospitalized for severe pneumonia according to ESTG. One study has shown that between $50 \%$ and $78 \%$ of patients with CAP may be hospitalized

Table 2 Empiric Antibiotic Prescribed for Patients Admitted to AURH for CAP from January to April 2019

\begin{tabular}{|c|c|c|c|c|}
\hline \multirow[t]{3}{*}{ Drug Regimens } & \multicolumn{2}{|c|}{ Mild Pneumonia } & \multirow[t]{3}{*}{ Severe Pneumonia } & \multirow[t]{3}{*}{ Total } \\
\hline & \multicolumn{2}{|c|}{ Used Antibiotics Within the Three Months } & & \\
\hline & Yes & No & & \\
\hline Ceftriaxone + azithromycin & $4^{\mathrm{a}}$ & $7^{\mathrm{a}}$ & 99 & $110(50.7)$ \\
\hline Co-amoxiclav plus clarithromycin or azithromycin & 11 & $6^{\mathrm{a}}$ & 13 & $30(13.8)$ \\
\hline Amoxicillin plus azithromycin or erythromycin & 3 & $2^{\mathrm{a}}$ & 4 & $9(4.1)$ \\
\hline Azithromycin & $5^{\mathrm{a}}$ & 7 & $8^{\mathrm{a}}$ & $20(9.2)$ \\
\hline Ceftriaxone & $19^{\mathrm{a}}$ & $12^{\mathrm{a}}$ & $16^{\mathrm{a}}$ & $47(21.7)$ \\
\hline Ceftazidime plus vancomycin & 0 & 0 & I & I \\
\hline
\end{tabular}

Notes: ${ }^{a}$ Inappropriate indications, according to Ethiopian standard treatment guideline; co-amoxiclav-amoxicillin plus clavulanate combination. 
unnecessarily when the CURB-65 score is not being used. $^{29}$ The cost of inpatient care for CAP is approximately greater compared to the outpatient setting. Therefore, high levels of non-compliance to ESTG by our physicians may have an important financial impact on the national healthcare system. Apart from the cost, hospitalization also increases the risk of thromboembolic events and super-infection by more drug-resistant hospital pathogen. $^{30}$

Adherence to empiric antibiotic guidelines for the management of patients with CAP has been demonstrated to reduce mortality and morbidity, ${ }^{11,12}$ shorten the length of hospital stay ${ }^{14,15}$ and decrease health care costs. ${ }^{17}$ Appropriate antibiotic prescription in hospitals ensures effective treatment of patients and administration of appropriate antibiotics within $4-8 \mathrm{hrs}$ is associated with $5-43 \%$ relative reduction of mortality. ${ }^{31,32}$ However, we found that $36.4 \%$ of the empiric antibiotic prescriptions did not adhere to our national treatment guideline. Inline with the current study; there are shreds of evidence to suggest that empiric antibiotic guidelines on the management of patients with CAP often poorly adhere to clinical practice. $^{14,16-21}$

Over $72.4 \%$ of patients diagnosed with a primary CAP were prescribed ceftriaxone alone or in combination with azithromycin. Of these, $19.4 \%$ of the prescriptions were over-prescribed for mild CAP. One study shows over $92 \%$ of CAP patients were prescribed ceftriaxone in the hospital. ${ }^{24}$ A study demonstrated that the use of broadspectrum cephalosporins in patients with mild-moderate CAP contributed to many discordant prescribing episodes. $^{27}$ Similarly, other studies have produced a concern that the use of third-generation cephalosporins is discordantly high and not in keeping with national and hospital guideline. ${ }^{24,33}$ These increase the financial cost of healthcare and impact the economy of the consumer. Also, the widespread use of third-generation cephalosporin (eg ceftriaxone) results in significant ecological adverse effects, specifically, the selection of drug-resistant organisms and the development of colonization or infection with multidrug-resistant bacteria. ${ }^{34}$

Some studies revealed possible barriers and challenges for poor adherence of healthcare professionals to treatment guideline. ${ }^{35}$ Models were developed to suggest that physicians fail to adhere to guidelines in the presence of an internal barrier that a cognitive (awareness or knowledge) or affective (attitude or motivation) component, or in the presence of an external barrier (patient, guideline and environmental factors) that restricts the professionals' ability. ${ }^{36-38}$ Implementation science indicates that factors determining healthcare professionals (HPs') adherence to treatment guideline can be linked to both individual, team and organizational level and are related to the context where the treatment and care is performed. ${ }^{39}$ While several studies describe barriers to guideline implementation, there is only little practical advice on how they should be translated into clinical practice-changing strategies. ${ }^{40}$

In conclusion, the pneumonia severity assessment tool was not used to guide treatment and antibiotics prescribing. The study indicated that adherence to CAP guidelines regarding the decision of hospital admission and the antibiotic selection was poor. Large proportions of the patients were unnecessarily hospitalized and over-prescribed broad-spectrum antibiotics. This may creates additional burden despite the increased focus on an antimicrobial stewardship program in Ethiopia. Further work is required to assess the feasibility and barriers to the use of national guideline in Ethiopian hospitals.

\section{Limitations}

We acknowledge the limitations of the current study, including 1) the estimates were based on one point in time observation completed in the three-month duration; 2) the pharmacists and the authors were not included in the antibiotic selection and it was the responsibility of the physician; 3) the study was not multi-sectoral observational studies.

\section{Abbreviations}

IDSA, Infectious Disease Society of America; CAP, community-acquired pneumonia; HAP, hospital-acquired pneumonia; VAP, ventilator-associated pneumonia; WHO, The World Health Organization; AURH, Ambo University Referral Hospital; ESTG, Ethiopian Standard Treatment Guideline; CURB-65, C-confusion; U-uremia or blood urea nitrogen (BUN); R-respiratory rate; B-Blood pressure and age greater than 65 .

\section{Data Sharing Statement}

All relevant data are within the paper. The SPSS data of individual patients are not permitted to be provided to other bodies, as indicated on ethical clearance. However, researchers who need further clarification can obtain anonymized data from the corresponding author on reasonable request. 


\section{Ethics Approval and Consent to Participate}

The study was conducted as per the declaration of Helsinki. Ethical clearance to conduct this study was secured and obtained from the ethical review board of the College of Medicine and Health Sciences of Ambo University with reference number AU/CHMS/SP/3025/ 2019. Participants were provided with an explanation of the study objective and were included in the study after written consent was obtained. The confidentiality of the study participants was maintained by assigning unique study identifiers during data collection and analysis.

\section{Acknowledgments}

The authors acknowledge Ambo University Referral Hospital for accessing the data. We were also grateful for the data collectors and supervisors for the carefully undertaking of their tasks.

\section{Author Contributions}

All authors made a significant contribution to the work reported, whether that is in the conception, study design, execution, acquisition of data, analysis and interpretation, or in all these areas; took part in drafting, revising or critically reviewing the article; gave final approval of the version to be published; have agreed on the journal to which the article has been submitted; and agree to be accountable for all aspects of the work.

\section{Funding}

No funding was received.

\section{Disclosure}

The authors declare that they have no conflicts of interest for this work.

\section{References}

1. Kalil AC, Metersky ML, Klompas M, et al. Executive Summary: management of Adults With Hospital-acquired and Ventilator-associated Pneumonia: 2016 Clinical Practice Guidelines by the Infectious Diseases Society of America and the American Thoracic Society. Clin Infect Dis. 2016;63(5):575-582. doi:10.1093/ cid/ciw353

2. Cilloniz C, Martin-Loeches I, Garcia-Vidal C, Jose AS, Torres A. Microbial etiology of pneumonia: epidemiology, diagnosis and resistance patterns. Int J Mol Sci. 2016;17(12):2120. doi:10.3390/ijms 17122120

3. Urba E. Prevalence and antibiotic resistance of stenotrophomonas maltophilia in respiratory tract samples: a 10-year epidemiological snapshot. Health Serv Res Managerial Epidemiol. 2019;6:1-9. doi: $10.1177 / 2333392819870774$
4. Mandell LA, Wunderink RG, Anzueto A, et al. Infectious Diseases Society of America/American Thoracic Society Consensus Guidelines on the management of community-acquired pneumonia in adults. Clin Infect Dis. 2007;14:S27. doi:10.1086/511159

5. Marrie TJ, Huang JQ. Epidemiology of community-acquired pneumonia in Edmonton, Alberta: an emergency department-based study. Can Respir J. 2005;12(3):139-142. doi:10.1155/2005/672501

6. Anevlavis S, Bouros D. Community acquired bacterial pneumonia. Exp Opin Pharmacother. 2010;11(3):361-374. doi:10.1517/146565 60903508770

7. French GL. The continuing crisis in antibiotic resistance. Int J Antimicrob Agents. 2010. doi:10.1016/S0924-8579(10)70003-0

8. Alós JI. Antibiotic resistance: a global crisis. Enferm Infecc Microbiol Clin. 2015;33(10):692-699. doi:10.1016/j.eimc.2014.10.004

9. Neu HC. The crisis in antibiotic resistance. Science. 1992;257: 1064-1073. doi:10.1126/science.257.5073.1064

10. Martens E, Demain AL. The antibiotic resistance crisis, with a focus on the United States. J Antibiot. 2017;70(5):520-526. doi:10.1038/ ja.2017.30

11. Aujesky D, Fine MJ. Does guideline adherence for empiric antibiotic therapy reduce mortality in community-acquired pneumonia? $\mathrm{Am}$ $J$ Respir Crit Care Med. 2005;172(6):655-656. doi:10.1164/rccm. 2506009

12. Dean NC, Bateman KA, Donnelly SM, Silver MP, Snow GL, Hale D. Improved clinical outcomes with utilization of a community-acquired pneumonia guideline. Chest. 2006;130(3):794-799. doi:10.1378/chest. 130.3.794

13. Menéndez R, Reyes S, Martínez R, de la Cuadra P, Vallés JM, Vallterra J. Economic evaluation of adherence to treatment guidelines in nonintensive care pneumonia. Eur Respir J. 2007;29(4):751-756. doi:10.1183/09031936.00052506

14. Dambrava PG, Torres A, Vallès X, et al. Adherence to guidelines' empirical antibiotic recommendations and community-acquired pneumonia outcome. Eur Respir J. 2008;32(4):892-901. doi:10.1183/ 09031936.00163407

15. Rossio R, Franchi C, Ardoino I, et al. Adherence to antibiotic treatment guidelines and outcomes in the hospitalized elderly with different types of pneumonia. Eur J Intern Med. 2015;26(5):330-337. doi:10.1016/j.ejim.2015.04.002

16. Arnold FW, LaJoie AS, Brock GN, et al. Improving outcomes in elderly patients with community-acquired pneumonia by adhering to national guidelines: community-acquired pneumonia organization international cohort study results. Arch Intern Med. 2009;169(16): 1515. doi:10.1001/archinternmed.2009.265

17. Brown PD. Adherence to guidelines for community-acquired pneumonia: does it decrease cost of care? Pharmacoeconomics. 2004;22 (7):413-420. doi:10.2165/00019053-200422070-00001

18. Delaney F, Jackson A. An audit of empiric antibiotic choice in the inpatient management of community-acquired pneumonia. Ir Med J. 2017;110(4):25.

19. Al-Abri SS, Al-Maashani S, Memish ZA, Beeching NJ. An audit of inpatient management of community-acquired pneumonia in Oman: a comparison with regional clinical guidelines. J Infect Public Health. 2012;5(3):250-256. doi:10.1016/j.jiph.2012.03.002

20. Lee RWW, Lindstrom ST. A teaching hospital's experience applying the Pneumonia Severity Index and antibiotic guidelines in the management of community-acquired pneumonia. Respirology. 2007;12 (5):754-758. doi:10.1111/j.1440-1843.2007.01121.x

21. Switzer GE, Halm EA, Chang CCH, Mittman BS, Walsh MB, Fine MJ. Physician awareness and self-reported use of local and national guidelines for community-acquired pneumonia. J Gen Intern Med. 2003;18 (10):816-823. doi:10.1046/j.1525-1497.2003.20535.x

22. Food, Medicine and Healthcare Administration and Control Authority of Ethiopia. Standard Treatment Guidelines For General Hospital Diseases Investigations Good Prescribing \& Dispensing Practices for Better Health Outcomes Stg. 2014. 
23. Nyamande K, Lalloo UG. Poor adherence to South African guidelines for the management of community-acquired pneumonia. South African Med J. 2007. doi:10.7196/SAMJ.650

24. Maxwell DJ, McIntosh KA, Pulver LK, et al. Empiric management of community-acquired pneumonia in Australian emergency departments. Med J Aust. 2005;183(10):520-524. doi:10.5694/j.132 6-5377.2005.tb07153.x

25. Brett J, Lam V, Baysari MT, et al. Pneumonia severity scores and prescribing antibiotics for community-acquired pneumonia at an Australian hospital. J Pharm Pract Res. 2013;43(2):97-100. doi:10. 1002/j.2055-2335.2013.tb00228.x

26. Collini P, Beadsworth M, Anson J, et al. Community-acquired pneumonia: doctors do not follow national guidelines. Postgrad Med J. 2007;83(982):552-555. doi:10.1136/pgmj.2006.056556

27. Mcintosh KA, Maxwell DJ, Pulver LK, et al. A quality improvement initiative to improve adherence to national guidelines for empiric management of community-acquired pneumonia in emergency departments. Int J Qual Heal Care. 2011;23(2):142-150. doi:10.1093/intqhc/mzq077

28. Grol R, Wensing M, Eccles M, Davis D. Improving Patient Care; the Implementation of Change in Health Care. John Wiley \& Sons:2013.

29. Nadarajan P, Wilson L, Mohammed B, Connor M, Lane SJ. Compliance in the measurement of CURB-65 in patients with community acquired pneumonia and potential implications for early discharge. Ir Med J. 2008;101(5):144-146.

30. Alikhan R, Cohen AT, Combe S, et al. Risk factors for venous thromboembolism in hospitalized patients with acute medical illness: analysis of the MEDENOX Study. Arch Intern Med. 2004;164 (9):963. doi:10.1001/archinte.164.9.963

31. Julián-Jiménez A, Palomo de Los Reyes MJ, Parejo Miguez R, Laín-Terés N, Cuena-Boy R, Lozano-Ancín A. Improved management of community-acquired pneumonia in the emergency department. Arch Bronconeumol. 2013;49(6):230-240. doi:10.1016/j.arbr.2012.12.003
32. Lee JS, Giesler DL, Gellad WF, Fine MJ. Antibiotic therapy for adults hospitalized with community-acquired pneumonia a systematic review. JAMA. 2016. doi:10.1001/jama.2016.0115

33. Robertson MB, Korman TM, Dartnell JGA, et al. Ceftriaxone and cefotaxime use in Victorian hospitals. Med J Aust. 2002;176 (11):524-529. doi:10.5694/j.1326-5377.2002.tb04549.x

34. Adam D. Global antibiotic resistance in Streptococcus pneumoniae. J Antimicrob Chemother. 2002;50(suppl 1):1-5. doi:10.1093/jac/dkf801

35. Eekholm S, Ahlström G, Kristensson J, Lindhardt T. Gaps between current clinical practice and evidence-based guidelines for treatment and care of older patients with Community Acquired Pneumonia: a descriptive cross-sectional study. BMC Infect Dis. 2020;20(1). doi:10.1186/s12879-019-4742-4

36. Scholes J, Cabanna M. Why don?t physicians follow clinical practice guidelines? A framework for improvement. Nurs Crit Care. 2007;281:1458. doi:10.1111/j.1478-5153.2007.00227.x

37. Cabana MD, Rand CS, Powe NR, et al. Why don't physicians follow clinical practice guidelines?: a framework for improvement. $J \mathrm{Am}$ Med Assoc. 1999;282(15):1458. doi:10.1001/jama.282.15.1458

38. Pollock AS, Legg L, Langhorne P, Sellars C. Barriers to achieving evidence-based stroke rehabilitation. Clin Rehabil. 2000;14 (6):611-617. doi:10.1191/0269215500cr369oa

39. Cosby JL. Improving patient care: the implementation of change in clinical practice. Qual Saf Heal Care. 2006;15(6):447. doi:10.1136/ qshc. 2005.016824

40. Van Bokhoven MA, Kok G. Van Der Weijden T. Designing a quality improvement intervention: a systematic approach. Qual Saf Heal Care. 2003;12(3):215-220. doi:10.1136/qhc.12.3.215
Patient Preference and Adherence

\section{Publish your work in this journal}

Patient Preference and Adherence is an international, peer-reviewed, open access journal that focusing on the growing importance of patient preference and adherence throughout the therapeutic continuum. Patient satisfaction, acceptability, quality of life, compliance, persistence and their role in developing new therapeutic modalities and compounds to optimize clinical outcomes for existing disease states are major areas of interest for the journal. This journal has been accepted for indexing on PubMed Central. The manuscript management system is completely online and includes a very quick and fair peer-review system, which is all easy to use. Visit http:// www.dovepress.com/testimonials.php to read real quotes from published authors. 